\title{
ROBUSTNESS OF INSTABILITY OF TWO-LAYER QUASI-GEOSTROPHIC EQUATIONS
}

\section{RONGFANG WANG}

Abstract. In this article, we investigate the instability of two-layer quasi-geostrophic equations, which is a prototypical geophysical fluid model. It is proved that any equilibrium which is sufficiently close to an unstable equilibrium is also unstable.

Mathematics subject classification (2010): 35B35, 76E20.

Keywords and phrases: linear instability, Lyapunov exponent, quasi-geostrophic equations.

\section{REFERENCES}

[1] T. Aubin, Nonlinear Analysis on Manifolds, Monge-Ampère Equations, Springer-Verlag, 1982.

[2] C. Bardos, Y. Guo, W. Strauss, Stable and unstable ideal plane flows, Chin. Ann. of Math., 23 (2002), 149-164.

[3] Y. Chen, L. Wu, Second Order Elliptic Equations and Elliptic Systems, American Mathematical Society, 1998.

[4] S. Friedlander, W. Strauss, M. Vishik, Robustness of instability for the two dimensional Euler equations, SIAM J. Math. Anal., 30 (1999), 1343-1355.

[5] A.Gill, Atmosphere-Ocean Dynamics, Academic Press, 1982.

[6] I. GohberG, M. KReIn, Introduction to the Theory of Linear Nonselfadjoint Operators, American Mathematical Society, 1969.

[7] Z. Lin, Nonlinear instability of ideal plane flows, 41 (2004), 2147-2178.

[8] A. Majda, A. BertozZI, Vorticity and Incompressible Flow, Cambridge University Press, 2001.

[9] A. Majda, X. WAng, Nonlinear Dynamics and Statistical Theories for Basic Geophysical Flows, Cambridge University Press, 2006.

[10] M. MU, Nonlinear stability criteria for motions of multilayer quasi-geostrophic flow, Science in China B, 34 (1991), 1516-1528.

[11] M. MU, Q. ZENG, T. SHEPHERD, Y. LIU, Nonlinear stability of multilayer quasi-geostrophic flow, J. Fluid Mech., 264 (1994),165-184.

[12] A. PAZY, Semigroups of Operators and Applications to Partial Differential Equations, SpringerVerlag, 1983.

[13] J. Pedlos Ky, Geophysical Fluid Dynamics 2nd ed., Springer-Verlag, 1987.

[14] M. Reed, B. Simon, Methods of Modern Mathematical Physics, Vol I, Academic Press, 1972.

[15] R. WANG, H. GAO, Nonlinear instability of Phillips model, accepted by Acta Mathematicae Applicatae Sinica (English Series), 2011. 